\title{
O Jovem Milton: a individuação entre a igreja e a educação social
}

\author{
Geraldo Leão' \\ Paulo César Rodrigues Carrano" \\ 'Universidade Federal de Minas Gerais (UFMG), Belo Horizonte/MG - Brasil \\ "Universidade Federal Fluminense (UFF), Niterói/RJ - Brasil
}

RESUMO - O Jovem Milton: a individuação entre a igreja e a educação social. O artigo discute os processos de transição para a vida adulta da juventude contemporânea, a partir de um caso escolhido entre os dados de um estudo sobre percursos biográficos de jovens participantes de um projeto social. O corpus empírico foi constituído por entrevistas biográficas aprofundadas, acompanhamento longitudinal das atividades cotidianas, desenhos de mapas de percursos por parte dos jovens e um grupo de discussão. A análise da trajetória do jovem Milton revela a formulação de estratégias para a superação de provas existenciais possibilitadas por aprendizagens que lhe permitiram constituir um capital social individualizado que o lançou para além das condiçõos objetivas do seu contexto social.

Palavras-chave: Juventude. Educação. Percursos Biográficos.

ABSTRACT - The Young Milton: the individuation between church and social education. This article discusses the processes of transition to adulthood of contemporary youth based on a selected case from a study of the biographical trajectories of young participants in a social project. The empirical corpus consisted of in-depth biographical interviews, longitudinal monitoring of daily activities, drawing maps of routes for young people and a group discussion. The analysis of the young Milton's trajectory shows his formulation of strategies to overcome existential situations. These strategies were possible through his process of learning that allowed him to constitute an individualized social capital, which propelled him beyond the objective conditions of his social context.

Keywords: Youth. Education. Biographical Trajectories.

Educação \& Realidade, Porto Alegre, v. 38, n. 3, p. 895-914, jul./set. 2013. 


\section{Introdução}

Este artigo foi produzido a partir de um recorte nos dados de uma pesquisa, realizada entre os anos de 2008 e 2009, sobre percursos biográficos de cinco jovens moradores de um morro da cidade de Niterói no Estado do Rio de Janeiro, participantes de um projeto social, desenvolvido pelo Museu de Arte Contemporânea (MAC) ${ }^{1}$ deste município. $\mathrm{O}$ estudo procurou compreender como esses jovens circulavam e se apropriavam da cidade, levando em consideração a rede de relações sociais e práticas que contribuíam para configurar o espaço social nos quais estavam imersos. As entrevistas individuais, registradas em vídeo, foram realizadas a partir de encontros semanais com cada jovem que variaram de cinco a seis semanas. Os jovens desenharam mapas mentais representando seus deslocamentos na cidade. Foram feitos também registros audiovisuais em locais indicados pelos sujeitos da pesquisa como significativos da sua circulação diária: escola, bairro, igreja, trabalho, etc. Além disso, foi realizado um grupo de discussão com os sujeitos da pesquisa.

Inicialmente, o texto discute alguns aspectos teóricos sobre a categoria trajetória e sua relação com a condição juvenil nas sociedades contemporâneas, com base em estudos sobre o tema. Em seguida apresenta o jovem Milton ${ }^{2}$ a partir de relatos significativos sobre sua vida que este compartilhou com a pesquisa. Por fim, a partir desta trajetória singular, o texto tece considerações sobre o tema na perspectiva de contribuir para a discussão de alguns aspectos da condição juvenil brasileira.

A tematização sobre os processos de transição de jovens para a vida adulta tem sido uma preocupação de alguns estudos mais recentes sobre a juventude contemporânea (Abrantes; Guerreiro, 2005; Arnett, 2001; Camarano, 2006; Leccardi, 2005; Pais, 2001). Para a educação, um olhar sobre os percursos biográficos de jovens, os diversos fatores que os constrangem e aspectos que orientam as escolhas e projetos vitais, bem como as estratégias que adotam na realização de seus anseios, pode contribuir para compreender as relações dos jovens com os processos educativos escolares e não-escolares. Adota-se uma perspectiva que procura compreender os sujeitos da educação a partir também de suas experiências plurais, tomando o educativo como um conjunto de processos de formação humana que se dá em diferentes tempos e espaços sociais.

Ao recuperar o percurso biográfico de um jovem, educador social e morador de uma comunidade de favela, além de compreender a relação entre percursos biográficos de jovens e condição juvenil em um contexto social específico, este texto, que não possui pretensões de generalização, explicita o papel ativo de jovens das camadas populares na construção de suas próprias biografias. Mesmo vivendo uma série de limitações quanto às condições de vida em contextos de grandes desigualdades sociais, os jovens fazem escolhas e traçam estratégias,

896 Educação \& Realidade, Porto Alegre, v. 38, n. 3, p. 895-914, jul./set. 2013 Disponível em: <http://www.ufrgs.br/edu_realidade> 
produzem saberes e criam alternativas de vida nem sempre marcadas pelo insucesso. Ao mesmo tempo se deparam com várias limitações que impõem um esforço redobrado para a efetivação de seus sonhos e projetos de vida, exigindo readequações de suas expectativas aos horizontes possíveis.

\section{Transições, Trajetórias e Juventudes}

De uma maneira geral, nas sociedades ocidentais modernas, a juventude tende a ser representada como um longo processo ao final do qual um indivíduo adquire as habilidades necessárias para desempenhar as funções da vida adulta. Nessa perspectiva, a transição juvenil é concebida a partir de alguns marcadores: o fim dos estudos, o começo da vida profissional, a saída da casa dos pais e a formação de um novo casal (Galland, 1996) ${ }^{3}$. Mas, se as fases da vida eram mais bem delimitadas em épocas passadas, hoje uma série de mudanças sociais e econômicas observadas nas sociedades contemporâneas contribui para confundir as diferentes etapas nos ciclos da vida (Camarano, 2006; Debert, 1999). Hoje, segundo Pais (2001), os jovens vivem experiências de trajetórias marcadas pela não-linearidade: “[...] são transições complexas e ziguezagueantes, sem rumo fixo ou pré-determinado". As escolhas dos jovens são mais passíveis de reversibilidade que em épocas anteriores, em que as trajetórias já não seguem um rumo pré-determinado.

Estes percursos biográficos não se definem apenas pelas condições objetivas, mas também pelos fatores subjetivos que configuram também as ações individuais, como os projetos, representações sociais e valores compartilhados que orientam as ações dos sujeitos ao longo da vida. Dubar (1998) contrapõe duas perspectivas de análise das trajetórias sociais. A primeira trata a questão como uma sequência de posições num ou mais campos da prática social (trajetórias objetivas), em contraposição a outras posições que buscam considerá-la como uma história pessoal cujo relato atualiza visões de si e do mundo (trajetórias subjetivas). Para o autor, deve-se considerar numa perspectiva relacional tanto as posições objetivas (escolares, profissionais) quanto às categorias de linguagem que os sujeitos utilizam para narrar suas histórias de vida em situações de entrevista.

Mas como conciliar relatos biográficos e processos estruturais de determinação social? Em A Ilusão Biográfica, Bourdieu (1983) defende que as biografias, como sequência cronológica e lógica dos acontecimentos e ocorrências da vida de uma pessoa, somente podem ser postuladas como construções dos sujeitos da pesquisa por meio de narrativas, o que lhes conferem a ilusão de um encadeamento coerente, coeso e atado por uma cadeia de interrelações. $\mathrm{O}$ autor nos alerta acerca dessa imagem, chamando a atenção para o fato de que as trajetórias se compõem de posições sucessivamente ocupadas por um indivíduo ou grupo social sujeito a constantes mudanças. Cabe então captar também as mudanças no espaço social ocupado pelos sujeitos, às condições ob-

Educação \& Realidade, Porto Alegre, v. 38, n. 3, p. 895-914, jul./set. 2013.

Disponível em: <http://www.ufrgs.br/edu_realidade> 
jetivas no qual ele se move. Pela análise das biografias individuais podemos compreender a trajetória social dos agentes e a sua relação com seu grupo social, captando como um determinado habitus, vinculado ao grupo social de origem, se sedimenta.

\section{Trajetórias Múltiplas e Individualizadas}

O sociólogo francês Bernard Lahire, na perspectiva bourdieusiana, mas avançando em sua abordagem, inserido no horizonte de uma sociologia das disposições, chama a atenção para as lacunas em termos de estudos e metodologias que captem a variação social dos comportamentos individuais (Lahire, 2004). Segundo ele, os estudos sociológicos tendem à abstração das singularidades individuais por meio de procedimentos generalizáveis (estatísticas, codificações, tipificações) permitindo compreender as relações sociais do ponto de vista das suas regularidades. Por outro lado, esses procedimentos de objetividade científica não permitem captar a pluralidade dos atores individuais. Em escala individual, não se pode reduzir os sujeitos e sua trajetória de vida às categorias criadas pelo cientista social pelo simples fato de que cada um é ao mesmo tempo várias coisas: o mesmo indivíduo é ao mesmo tempo escolarizado, protestante, artesão e assim por diante. Portanto, no indivíduo o social reside em uma versão dobrada, que não substitui o conhecimento por abstração dos fatos sociais particulares, mas que permite refinar a sua análise.

Para Lahire (2004) a compreensão das ações dos atores em contextos diversos não pode prescindir da consideração do passado incorporado dos atores individuais em sua socialização. As experiências pelas quais os indivíduos passaram ao longo de sua vida constituem formas de pensar, sentir e agir - um patrimônio de disposições - que eles usam face às novas situações com as quais se deparam na vida. Tais disposições não são propriedades imutáveis, passíveis de serem transpostas a qualquer situação. Elas são ativadas ou inibidas dependendo do contexto de interações, relações e laços de interdependência em que os sujeitos estão inseridos no momento atual. Os atores podem assim tomar atitudes imprevisíveis, diferentes e contraditórias, o que nos coloca a tarefa de compreender tal heterogeneidade. Para ele, as disposições são sempre disposições sob condição, o que exige observar as práticas dos atores, os contextos em que se dão e as relações em que estão inseridas (Lahire, 2004, p. 54-59).

Os indivíduos não são sempre guiados por hábitos ou esquemas de ação homogêneos e coerentes, a não ser em condições históricas e sociais específicas em que o ator tenha sido submetido a processos de socialização coerentes, o que se torna uma raridade em face da diversidade de contextos sociais e de experiências socializadoras típicas das sociedades contemporâneas. Estamos diante, portanto, de um ator plural (Lahire, 2002). 
Não se trata de conceber uma imagem do ator como algo determinado por um conjunto de disposições adquiridas na socialização passada. De acordo com o autor, o presente se constitui como um filtro capaz de ativar ou inibir determinadas disposições. Em face das mudanças de contexto, o indivíduo pode assumir diferentes estratégias, desde a adaptação, até a fuga ou a resistência. Os esquemas de ação constituemse de disposições que muitas vezes se encontram em estado de latência, podendo ser reativados em face de determinados contextos ou momentos do ciclo da vida.

Neste sentido, os eventos vividos por cada jovem estão em parte determinados pelos recursos disponíveis - econômicos, culturais, sociais - e pela disposição do seu grupo social de origem em investir tais recursos em determinado campo - escolar, profissional, cultural, esportivo etc. Mas dependem também do sentido e das disposições acionadas pelos indivíduos, do contexto em que cada um se encontra em um momento da vida, das referências e instituições de apoio a que têm acesso, ou seja, do conjunto de experiências e relações sociais em que eles se inserem.

\section{Por uma Sociologia do Indivíduo}

Como podemos compreender fenômenos sociais mais amplos a partir da reconstituição de uma trajetória específica? Essa é a proposta de uma sociologia do indivíduo. Nessa perspectiva é possível compreender uma sociedade na escala individual (Martuccelli, 2007). Colocar o indivíduo no centro da análise social deve corresponder tanto à descrição do trabalho do indivíduo para fabricar-se como sujeito, quanto, a partir de uma visão sócio-histórica, à abordagem do tipo de indivíduo que é estruturalmente fabricado em uma sociedade.

Araújo e Martuccelli (2010) advogam que todos os indivíduos, na sua tarefa de se constituírem como sujeitos, estão submetidos a um conjunto de provas estruturais a partir de suas diversas posições sociais. Segundo os autores, trata-se de "[...] desafios históricos, socialmente produzidos, culturalmente representados, desigualmente distribuídos, que os indivíduos estão obrigados a enfrentar no seio de um processo estrutural de individuação" (Araújo; Martuccelli, 2010, p. 77-91). Nessa perspectiva, a noção permite compreender o processo de autofabricação dos sujeitos, na articulação entre os processos sociais e o modo como os indivíduos enfrentam tais provas a partir de suas experiências sociais.

A noção pressupõe quatro características: a) Uma dimensão narrativa para dar conta das inúmeras experiências individuais vividas pelos indivíduos postos à prova; b) Ela é tida como uma tarefa dos indivíduos que se veem obrigados a enfrentá-las; c) Elas estão vinculadas a processos de avaliação e diferenciação (de gênero, de classe, de raça), em que os sujeitos podem sair vitoriosos ou fracassados dependendo do tipo de provas a que são submetidos e aos diferentes recursos que mobi-

Educação \& Realidade, Porto Alegre, v. 38, n. 3, p. 895-914, jul./set. 2013.

Disponível em: <http://www.ufrgs.br/edu_realidade> 
lizam para fazer frente a elas; d) Não designam qualquer tipo de desafio, mas dizem respeito a um conjunto de traços estruturais em uma sociedade, podendo variar desde provas institucionalizadas (escola, trabalho, família), àquelas relativas a laços sociais (relacionadas aos coletivos, às normas, aos outros) ou afetivos.

As provas se diferenciam de acordo com os contextos sociais e com a etapa de vida (inscrição temporal), mas, no nível individual, elas se singularizam a partir das trajetórias vividas, etapas em que se combinam os erros e acertos, o destino e a sorte, as oportunidades e as dominações, os acidentes e os condicionamentos. Nessa perspectiva é possível abordar sociologicamente a singularidade das trajetórias sem abdicar de uma visão estrutural, o que permite explicar porque indivíduos que dispõem dos mesmos recursos e cujas posições sociais são, aparentemente, muito similares revelam diferenças muito importantes na hora de enfrentá-las.

\section{Entre Desejos, Limites e Possibilidades}

Um último aspecto a ser considerado refere-se ao contexto social em que se configuram as condições para que os jovens construam suas trajetórias. Hoje temos a sensação de que as vidas das pessoas estão sujeitas a um maior grau de imprevisibilidade e de que dependem mais das escolhas individuais. As transformações sociais, culturais e econômicas que afetaram as sociedades contemporâneas nos remetem à imagem de indivíduos com um leque maior de possibilidades de escolhas. Ao mesmo tempo, as pessoas assumem maiores responsabilidades sobre a tomada de decisões corretas, a capacidade em contornar os imprevistos e a habilidade individual de tirar o melhor proveito em cada situação.

A ideia de que as trajetórias são cada vez mais individualizadas pode nos levar a uma exacerbação da autonomia individual em detrimento da constatação de que os indivíduos não vivem no vazio. O contexto social impõe limites e configura as escolhas e estratégias de ação possíveis para cada um. São individualizações estruturadas (Pimenta, 2007), pois são conformadas pelo indivíduo, mas a partir de um conjunto de laços de interdependência, redes de relações sociais, disposições internalizadas.

Para os jovens com maiores recursos sociais, culturais e econômicos, as possibilidades de usufruir positivamente da reflexibilidade e da experimentação proporcionada pelas sociedades contemporâneas são maiores, possibilitando a construção de percursos biográficos autônomos. Esses têm mais condições de desenvolver a capacidade de viver riscos e de dirigir suas vidas numa ideia de "[...] futuro sem projeto" (Leccardi, 2005, p. 51). Porém, para os pobres, majoritários em contextos como da sociedade brasileira, o futuro traz uma forte carga de sofrimento sobre o presente.

900 Educação \& Realidade, Porto Alegre, v. 38, n. 3, p. 895-914, jul./set. 2013 Disponível em: <http://www.ufrgs.br/edu_realidade> 


\section{A Trajetória de Milton: do morro para além do morro}

A trajetória de vida narrada por Milton pode trazer alguns elementos que permitem compreender as experiências e práticas sociais como processos educativos em que os jovens se inserem. Pode-se assim, a partir das perspectivas teóricas, compreender como esse jovem se faz como educador, ao mesmo tempo em que contribui para o processo de formação de outros jovens.

Milton se autodeclarou negro, tinha 24 anos na época das entrevistas e morava sozinho no Morro do Palácio, desde que o irmão casara. Ele namorava uma jovem do morro, membro da mesma igreja evangélica que ele, com quem estava fazendo planos de se casar em breve. A sua participação no projeto de agenciamento sociocultural se iniciou entre os 14 e 15 anos. Milton concluiu o ensino médio na modalidade de magistério e atuava como educador social em projetos desenvolvidos pelo MAC.

Ele se definia como uma pessoa calma e de fácil relacionamento. Dono de um discurso bem articulado, uma marca desse jovem revelada durante o processo de entrevistas foi o tom reflexivo com o qual conduzia suas respostas sobre questões que tratavam de assuntos os mais diversos: momentos importantes de sua vida, interações e amizades, lugares e pessoas de referência, valores etc. A sua atuação como líder da mocidade numa igreja evangélica e como educador, talvez explique a predominância dessas disposições pessoais durante as entrevistas realizadas.

Foram realizadas ao todo seis entrevistas, cinco delas no campus universitário e uma em um morro frequentado por evangélicos como um local de orações. Os depoimentos de Milton enfatizavam o seu envolvimento com o lugar onde vivia, principalmente por meio da sua atuação em projetos sociais e como liderança dos jovens na igreja onde atuava. Esses espaços permitiam que ele partilhasse os problemas e demandas do morro, vinculando essa experiência com o seu trabalho como educador social.

\section{Infância}

Milton se lembrava da infância como uma época mais inocente do que hoje, quando as crianças eram mais lúdicas e criativas. Sua vida se passava basicamente entre a casa, a escola e o trabalho junto com o pai que era pescador. Suas amizades e atividades de lazer nessa época se desenvolviam nos espaços da casa e da escola, com o irmão e com alguns vizinhos que residiam mais próximos. Segundo declarou, havia uma preocupação dos seus pais em criar uma rede de proteção e cuidado com os filhos que envolvia a família, a escola, a igreja e o trabalho.

Ao recordar a sua infância no morro, Milton nos remete à ideia da importância da preservação de uma imagem positiva diante dos colegas e vizinhos:

Educação \& Realidade, Porto Alegre, v. 38, n. 3, p. 895-914, jul./set. 2013

Disponível em: <http://www.ufrgs.br/edu_realidade> 
Infância na comunidade é complicado, né, cara?! A coisa é meio de selva! Você tem que ser bom. O cara, prá ser legal na infância, o cara tem que ser bom de futebol, o cara tem que ser bom de briga e tal... Tem que ser bom na escola. Tem que ser bom numa série de coisas. Tem que mostrar um determinado valor dentro da comunidade. Que na nossa infância a gente chamava de moral. O cara tem que ter moral!

Esse sentido do termo é construído cotidianamente nas interações e encontros rotineiros no lugar de moradia e na escola, nas brigas e nas práticas de esporte e de lazer, nos quais os sujeitos passam a ocupar um lugar reconhecido pelo grupo de amigos.

Outro sentido para ter moral era dado por referência ao pai, instância moral de uma ética masculina. Segundo seu depoimento: "Ele falava que, com ele eu ia ter que aprender a ser homem" (Carrano, 2008, p. 5). Milton atribuía ao pai uma importância muito grande em sua infância, como referência de valores morais: trabalhador, provedor, reto, honesto. Interessa aqui registrar esse segundo sentido do termo ligado à imagem paterna que garante a coesão do grupo familiar, como espelho de uma moral das famílias pobres (Sarti, 1996).

Por fim, um último sentido para ter moral referia-se à possibilidade de se firmar pela adesão a práticas consideradas ilícitas, especialmente o tráfico de drogas. Segundo ele, já se apresenta para as crianças moradoras do morro a possibilidade de escolher entre se inserir ou não no movimento ${ }^{4}$. Ter moral, nesse caso, representa ter visibilidade, seja pela reputação de ser uma pessoa valente - bom de briga - seja pela posse de determinados bens de consumo que o ingresso no mundo do crime possibilita.

Há nesse sentido para o termo, a ideia do tráfico como uma escolha face ao risco de ser vítima da violência de grupos específicos - polícia, grupos armados e traficantes - ou ao risco de se tornar invisível (Peralva, 2000). O tráfico nesse caso torna-se um refúgio relativo, uma possibilidade de administrar e conviver com o risco que se apresenta como opção desde a infância. Entre não correr riscos e permanecer na invisibilidade e na pobreza, vivendo como simples trabalhador, ou se tornar alguém visto e valorizado pelos colegas e vizinhos, ostentando a posse de alguns bens de consumo - carros e motos, roupas de grife e celulares - a segundo opção torna-se um atrativo para alguns jovens e crianças.

\section{Pai: a imagem quebrada e o amadurecimento precoce}

Como já antecipamos, o pai era o depositário de algumas disposições e valores, representando em sua infância um modelo a seguir que perdura até hoje. Ele se referia ao pai como alguém que tinha um jeito meio firme, com uma formação rígida das famílias tradicionais. O pai sempre trabalhou como pescador e embora tivesse pouco contato durante o dia com os filhos devido à sua atividade, teve uma importância central na sua formação moral. 
Essa imagem foi abalada quando os pais se separaram. Aos 11 anos de idade o pai se envolveu com uma mulher bem mais nova, da idade de sua irmã e se separou da sua mãe. Esse episódio significou para Milton um momento de crise. Em primeiro lugar porque provocou a quebra da imagem paterna e os valores associados a ela como modelo de ser homem - ser reto, não trair os amigos, não trair os meus princípios, respeitar os valores dos outros, os direitos das pessoas. Em segundo lugar, a experiência da separação teve esse significado porque trouxe dificuldades financeiras para a família. A mãe era aposentada por invalidez e o pai era o único que trabalhava. A sua saída do lar, mesmo continuando a contribuir financeiramente, provocou uma queda na renda familiar que perdurou cerca de dois anos.

Milton tinha um irmão e uma irmã dessa união. Com a separação, o irmão foi morar com o pai. A irmã, por sua vez se casou, deixando-o sozinho com a mãe. Com passar do tempo o pai deixou de contribuir com a manutenção da casa e a crise se agravou. Para pagar os remédios, a mãe foi obrigada a vender alguns móveis e utensílios da sua casa. Nesse período ocorreu a única interrupção na trajetória escolar de Milton que durou cerca de dois anos. Essa fase não foi muito referida por ele, que se limitou a atribuir o abandono da escola à necessidade de cuidar da mãe.

Quando a mãe vendeu a casa e se mudou para o interior para viver com parentes, Milton viveu durante um período com o irmão e a madrasta. Algum tempo depois, devido a conflitos com a madrasta, eles foram convencidos pelo pai a se mudarem para a casa atual que Milton mantém no Morro do Palácio. Posteriormente, o irmão se casou e ele permaneceu morando sozinho.

\section{Trajetória Escolar: o sucesso relativo de um bom aluno}

Ao falar de sua vida escolar Milton revelou uma trajetória sem grandes dificuldades. Com exceção do momento em que deixou os estudos na quinta série, o seu percurso escolar não teve outras interrupções.

A sua primeira recordação refere-se à entrada na primeira série do Ensino Fundamental. Milton relatou que foi matriculado na turma avançada do primeiro ano do ensino fundamental, pois no momento da matrícula sua mãe fez com que a escola soubesse que ele já sabia contar de um a dez em inglês, ainda que o conhecimento da língua inglesa não passasse desta habilidade decorada. Para a professora, contudo, isso teria sido a demonstração de uma maior aptidão para os estudos que justificava a inscrição numa turma avançada. Dessa forma, a sua entrada na escola reforçou positivamente a sua imagem como aluno, com boas expectativas quanto ao seu desempenho.

Como foi relatado a única interrupção na sua trajetória escolar ocorreu na quinta série, durante a fase de separação dos pais e do adoecimento da mãe. Durante cerca de dois anos ele deixou de frequentar a 
O Jovem Milton

escola e os professores mandavam recados pelo irmão para que ele voltasse a estudar. Não houve relatos sobre o seu retorno, mas tudo indica que ele não teve grandes dificuldades quando reassumiu sua carreira escolar numa escola estadual situada fora do morro que frequentou da quinta série ao Ensino Médio.

Milton tinha lembranças positivas da escola. Além de um local de aprendizagem e de fazer amigos, a escola era lembrada como um lugar de escape. Segundo ele disse: "A escola me fazia sair de fora daquele âmbito só de favela" (Carrano, 2008, p. 56). Nesse sentido ele valorizava a possibilidade de encontrar pessoas de fora da comunidade, mesmo havendo conflitos entre alunos moradores de diferentes favelas da cidade na escola em que foi estudar.

As referências desse jovem em relação à sua experiência escolar nos remetem à perspectiva de Lahire (1997) sobre as trajetórias escolares de estudantes dos meios populares. Indo além da noção de transmissão do capital cultural, calcado no habitus do grupo familiar, esse autor vê a socialização escolar como a construção da experiência de ser estudante, que se produz no contexto de uma configuração social dada na qual interferem várias dimensões da vida dos sujeitos: relações sociais, dinâmicas familiares, relações de gênero, redes de sociabilidade etc. A integração social e simbólica da criança no universo escolar resulta de configurações familiares heterogêneas, onde podem operar elementos contraditórios a partir dos quais se formam as suas habilidades e disposições. Apesar das dificuldades vividas por Milton, vários fatores desenvolveram nele a disposição para os estudos e a valorização do universo letrado, tais como: a valorização materna, as expectativas positivas alimentadas no momento de sua inserção na escola, as experiências posteriores nos projetos sociais e a participação na igreja. São as razões do improvável, como nos lembra Lahire (1997).

\section{Adolescência: produzindo-se como educador social e voluntário}

O funk e a participação em projetos sociais são duas experiências que marcaram a adolescência de Milton. $\mathrm{O}$ seu envolvimento com o funk teve menor relevo nos seus depoimentos, embora pareça ter um significado importante nessa fase da sua vida como fonte de amizades e reconhecimento pessoal no morro. Sua ruptura posterior com essa prática cultural se deu de uma forma gradativa, enquanto ele se envolvia com a igreja e com os projetos sociais.

Desde a adolescência Milton participou de vários projetos sociais. Sua primeira experiência foi no ano de 1998, aos 14 anos de idade, em um Curso de Vidraçaria de um programa federal chamado Capacitação Solidária ${ }^{5}$. Em 1999, participou de uma primeira experiência do projeto desenvolvido pelo MAC no Morro do Palácio, quando tinha então 15 anos. Milton permanece até hoje no projeto, agora, na condição de monitor. A essas primeiras experiências seguiram-se um curso de ca-

904 Educação \& Realidade, Porto Alegre, v. 38, n. 3, p. 895-914, jul./set. 2013.

Disponível em: <http://www.ufrgs.br/edu_realidade> 
pacitação para trabalhar na Caixa Econômica Federal em 2000 e a participação em um projeto chamado Jovens pela Paz ${ }^{6}$ durante dois anos. Posteriormente ele participou como monitor no Programa Agente Jovem de Niterói entre 2003 e 2006. Pelo seu relato, essa foi a sua primeira experiência como educador social.

Ao final do referido curso de vidraçaria, os participantes tiveram a oportunidade de conhecer o MAC que se localiza defronte ao Morro do Palácio, mas que nunca havia sido visitado por Milton ou seus colegas. Nesta visita foram convidados a participar de um novo projeto que se iniciaria no MAC. Esse primeiro momento contou com a adesão de alguns jovens que frequentaram o projeto durante cerca de quatro meses. Segundo ele, essas idas ao MAC eram sem compromissos; só para aprender. Esse foi o embrião do Projeto, no qual Milton permanecerá e do qual se tornará monitor.

Durante os seis primeiros meses de funcionamento do projeto, cada jovem ganhava uma bolsa de 50 reais. Ao final da experiência, alguns deles continuaram participando das atividades, mesmo sem receber uma ajuda financeira para isso. Esse grupo passou a comercializar seus produtos na loja do MAC, que conseguiu algumas parcerias para dar continuidade à ação, situação que perdurou até a época das entrevistas.

No período das entrevistas, Milton desenvolvia várias ações vinculadas diretamente ao MAC ou por intermédio dele. Ele era estagiário em atividades internas e monitor em oficinas e trabalhos educativos. Estava também envolvido em uma oficina de papel reciclado desenvolvida no Morro do Palácio voltado para crianças e adolescentes e em um projeto social desenvolvido em Vigário Geral? . Além disso, trabalhava como voluntário em uma ONG que produzia e comercializava alimentos orgânicos e artesanato de reciclagem.

Grande parte das atividades cotidianas de Milton girava em torno do Projeto, ao qual ele atribuía uma grande importância na sua trajetória de vida. Um primeiro aspecto ressaltado por ele referia-se ao impacto no plano dos hábitos e gostos pessoais, como uma maior concentração na escola, nas atividades de estudos e mudanças de hábitos em pequenas coisas do cotidiano. Além disso, segundo ele, a experiência proporcionou ampliar a sua bagagem social, o que parece se referir ao conjunto de conhecimentos e habilidades que lhe permitiram ampliar a sua rede de contatos e suas oportunidades de trabalho como educador social.

Esse longo período como aluno ou monitor em projetos sociais parece corresponder a um processo de socialização no qual ele desenvolveu hábitos e valores, além de habilidades e competências que foram importantes na construção de sua identidade profissional como educador social. Uma das marcas desse processo de produção de si como jovem/monitor de projeto é a disposição para se envolver em múltiplas atividades. A heterogeneidade não se refere apenas às atividades, tem- 
pos e espaços frequentados, mas à forma de inserção nessas ações, o que lhe confere diferentes identidades. Milton dizia: "Sou várias coisas: monitor, estagiário, arte-educador... Em cada lugar eu sou uma coisa” (Carrano, 2008, p. 75).

Isso nos remete à figura do homem plural teorizada por Lahire (2002). Em sua proposta de desenvolver uma sociologia da ação que permita captar a variação dos comportamentos individuais esse autor nos chama a atenção para a heterogeneidade de disposições incorporadas pelo ator tanto em face de sua socialização anterior, como diante da pluralidade de contextos e práticas sócio-culturais que marcam as experiências humanas na contemporaneidade. Da mesma forma, podemos pensar na imagem do jogo do eu tecida por Melucci (2004) ao tratar da questão das múltiplas identidades nas sociedades complexas. Essas imagens de um eu múltiplo não devem nos levar a pensar em um sujeito fragmentado, incapaz de construir um sentido de unidade de si. Ao contrário, tal multiplicidade exige do ator o trabalho de produção de si, uma capacidade de eleger suas referências em meio a uma gama variável de possibilidades.

Ao falar de seu trabalho, Milton parecia buscar uma síntese entre essas múltiplas e heterogêneas experiências: "Se você me perguntar qual é a minha profissão eu falo que eu não sei. Eu acho que eu sou um bem intencionado que consigo ganhar a vida fazendo essas coisas... Trocando as experiências" (Carrano, 2008, p. 77). Para ele o trabalho como educador social estava ligado a aspectos como ajudar as pessoas, possibilitar o crescimento pessoal e do outro, ser um facilitador e um multiplicador de aprendizados na comunidade. Ao falar de sua atuação em Vigário Geral, por exemplo, ele fazia referências a passagens e personagens religiosos, a valores cristãos, mas também a categorias ligadas à formação no magistério ou nas experiências vinculadas ao MAC.

Milton via como uma grande responsabilidade as suas atividades como educador, uma vez que se sentia na obrigação de corresponder às expectativas que o MAC e os educadores depositavam nele. Segundo ele: "Eles depositaram muita fé, no caso, né? Depositaram trabalho, depositaram tempo em estar me capacitando e agora é o tempo de estar fazendo alguma coisa [...] como as pessoas esperam, né?" (Carrano, 2008, p. 69). A confiança depositada nele trazia como contrapartida o peso da correspondência. Se um alto grau de responsabilidade parece ser uma marca pessoal em Milton, essa disposição pode estar também calcada nas suas várias passagens por programas sociais que tendem a reforçar tal aspecto. Por outro lado pode estar associada também à necessidade de preservar o lugar conquistado, mantendo o vínculo com uma rede de educadores e as oportunidades de trabalho que isso proporciona.

Trata-se de saber se essa inserção duradoura dos jovens pobres em projetos sociais - jovens de projetos - e para alguns, a permanência na condição de educador-mediador social é capaz de assegurar a construção de uma identidade profissional futura. Podemos dizer que Milton 
tinha uma trajetória de sucesso nos projetos em que esteve vinculado. No entanto, ele parecia transitar entre uma gama infinita de afazeres cotidianos e as incertezas das atividades que exercia como educador social.

Como dissemos além de sua atuação nos projetos sociais diretamente vinculados ao MAC, Milton era voluntário de uma ONG que desenvolvia ações na linha da reciclagem de materiais e produção de alimentos orgânicos. Essa ONG promovia semanalmente uma feira de produtos orgânicos e artesanais, além de um café onde ocorriam alguns debates sobre temas diversos. Assim, todos os sábados pela manhã, a partir das sete horas Milton podia ser encontrado na ONG atendendo aos clientes e divulgando o trabalho dessa associação. Segundo ele, esse era um espaço legal, frequentado por um público diferenciado e com uma proposta com a qual ele se identificava.

Embora se identificasse com a proposta, ele não se considerava um ecologista. Pelo seu relato, não havia uma vinculação mais estreita com essa ONG. Havia mesmo uma postura de distinção frente a outras experiências tais como na igreja ou nos projetos do MAC em que Milton possuía uma intervenção mais ativa. Podemos dizer que tal atividade era vista por ele como uma espécie de militância social importante para manter seus vínculos com esse universo das ONGs e dos projetos sociais. Nesse sentido, o fato de não contar com um emprego duradouro, em tempo integral, impunha a necessidade de se inserir em várias experiências numa espécie de empreendedorismo social que estabeleceu para si como estratégia de inserção em redes sociais diferenciadas daquelas que possuía em seu local de moradia. Nesse sentido ele vive os mesmos dilemas do trabalho autônomo ou voluntário cuja marca característica é a precariedade em relação aos vínculos profissionais, a imbricação entre tempos de lazer e trabalho e a autorresponsabilização em termos de desempenho.

\section{A Igreja: o poder da palavra}

A Igreja Evangélica, que Milton frequentava praticamente todos os dias, tinha uma grande importância em sua vida. Quando não estava nos cultos ou reuniões, geralmente ele estava envolvido em atividades com outras pessoas do seu grupo religioso: estudos, aconselhamentos a jovens e a iniciantes, lazer etc. Ela era um lugar privilegiado para encontrá-lo ou obter informações sobre seu destino. Como a família da sua noiva também participava da igreja, o percurso da sua casa, ao templo e à casa da noiva era praticamente uma rotina.

Milton entrou para a igreja aos 20 anos. Segundo ele foi um processo lento de aproximação, que começou aos poucos por curiosidade. Houve um movimento de conversão individual, que remetia primeiro à descoberta de Deus como referência na vida. Essa ideia da conversão como uma escolha do indivíduo, para além da fidelidade a uma instituição religiosa, estava presente nas práticas de comprar CDs e DVDs 
de pastores de diferentes igrejas e no hábito de se retirar para um monte nos arredores da cidade frequentado por fiéis de diferentes igrejas para orar e, segundo disse, ficar mais perto da natureza e de Deus.

A igreja o inseria em uma rede de amigos importantes para ele. Em diversos momentos Milton relatou situações de interação com os membros da igreja, principalmente com os jovens, que extrapolavam o espaço restrito dos cultos e reuniões. Sair para procurar produtos evangélicos, promover festas e almoços, visitar outras igrejas e passear foram atividades coletivas frequentemente citadas que evidenciam a dimensão significativa das redes de sociabilidade articuladas a partir do espaço-tempo religioso.

Além disso, o trabalho na Igreja envolvia também um elemento de realização pessoal e reconhecimento social. No morro, Milton era identificado como uma liderança religiosa juvenil. Segundo ele, o seu trabalho como conselheiro e instrutor da igreja junto aos jovens adquiria também uma dimensão social. Parecia haver, nesse caso, uma complementaridade entre a sua atuação como educador e como membro da igreja.

Nos cultos ele podia fazer uso da palavra. Diversas vezes Milton relatava os momentos em que foi convidado a fazer a preleção do dia, o que envolvia um misto de responsabilidade e satisfação: "Quando você sente que foi bem, acho que tira um peso muito grande de cima de você" (Carrano, 2008, p. 45). Como vimos anteriormente, havia por parte dele uma valorização da dimensão comunicativa que se manifestava não apenas nas práticas religiosas - preleções, aconselhamentos aos jovens, reflexões em grupos -, mas também em outras esferas como nas oficinas que ministrava no projeto social.

Quanto a esse aspecto a sua postura revelava ambiguidades. Nos seus depoimentos acerca de suas atividades como educador social havia uma abertura maior para a diversidade da condição juvenil, uma disposição maior para aceitar as diferenças quando falava, por exemplo, do funk e da inevitável manutenção de relações de cordialidade com amigos e conhecidos que ingressaram no movimento do tráfico de drogas. De outra parte, quando se referia aos jovens do ponto de vista de sua atuação na igreja, emergia uma tendência a manifestar uma visão preconcebida da juventude. Em alguns momentos das entrevistas ele manifestou as seguintes opiniões: "Os jovens estão com o hormônio à flor da pele", "Querem ser adultos, mas não querem as responsabilidades da vida adulta" (Carrano, 2008, p. 24-25). Nesse momento, Milton parece assumir um tom moralizador que o aproximaria do discurso institucional de sua igreja. As responsabilidades assumidas ao longo da vida - cuidar da mãe, morar sozinho, corresponder às expectativas dos projetos sociais, liderar os jovens na igreja - pareciam se aplicar também à imagem que tecia sobre a condição juvenil no morro, como se o amadurecimento precoce experimentado pessoalmente correspondesse a uma trajetória natural dos jovens pobres.

908 Educação \& Realidade, Porto Alegre, v. 38, n. 3, p. 895-914, jul./set. 2013 Disponível em: <http://www.ufrgs.br/edu_realidade> 
Relembrando sua vida no morro, Milton relatou que ele e alguns colegas faziam questão de ser um exemplo na comunidade. Segundo ele, em contraposição ao jogador de futebol ou ao traficante como modelos de sucesso, ele se preocupava em ser uma referência de conduta para os jovens do lugar. No entanto, esse esforço para manter tal imagem não se fazia sem o conflito em relação aos custos que isso acarretava para os seus projetos futuros, pois o fato de assumir várias tarefas exigia se sacrificar em relação aos seus projetos pessoais. Ele se utilizou da imagem de uma vela, que se consome no ato de iluminar e clarear o caminho para os outros, para traduzir esses sentimentos. Ao se dedicar tanto aos outros - à igreja, ao trabalho voluntário, aos projetos sociais, ao resgate dos jovens que erraram de caminho - ele sentia que poderia estar deixando de cuidar de si.

\section{Projetos de Vida e seus Dilemas: "Se consumir pelos outros?"}

Permanecer no morro, morando sozinho, foi narrado como sendo uma escolha que não corresponderia ao projeto que sua família teria para ele. Para muitas famílias, sair do morro é uma forma de garantir a segurança do grupo e novas oportunidades de mobilidade social. No seu caso, restava apenas ele, pois o pai e os irmãos já tinham se mudado da comunidade. Milton quase foi morar com o pai, que é pescador em Sepetiba, o que significaria dar continuidade à trajetória profissional paterna abrindo mão de outros projetos de vida. Segundo seu relato:

Eu seria só o filho do pescador! Nem pescador eu seria. Aqui eu posso correr atrás! Aqui eu sou o monitor. Aqui eu sou o Milton, que cuida sozinho da casa. Aqui eu sou estagiário. Já mudou bastante para mim, entendeu! Do que eu ser o filho do pescador. Aqui eu sou o menino lá da ONG que vai lá. Eu sou o rapaz que coordena a juventude da Igreja.

Milton parece contrapor o destino da identidade única de pescador que o morar com o seu pai proporcionaria com as possibilidades de vivenciar múltiplas esferas de pertencimento - identidades múltiplas (Carrano, 2000) -, ser um e muitos ao mesmo tempo. Além de ser um lugar onde se sentia acolhido, na qual tinha amigos e estava inserido em diferentes grupos sociais, o morro representava para ele maiores oportunidades de trabalho e reconhecimento. Permanecer no morro para ele significava manter a sua independência e investir em planos futuros, colhendo os frutos de sua dedicação, principalmente no que se refere aos projetos desenvolvidos pelo MAC.

Assim, apesar dos problemas que reconhecia no morro como a violência e o desemprego, a sua permanência acenava para ele mais possibilidades de estudar e se desenvolver profissionalmente. Entre as incertezas do trabalhar no mar e as incertezas do morar no morro, ele se sentia mais seguro na comunidade, onde já havia conquistado confiança, reconhecimento e respeito: "Seria trocar (um projeto) um pouco duvidoso, por (um projeto) um pouco menos duvidoso" (Carrano, 2008, p. 88).

Educação \& Realidade, Porto Alegre, v. 38, n. 3, p. 895-914, jul./set. 2013

Disponível em: <http://www.ufrgs.br/edu_realidade> 
O Jovem Milton

Com relação ao futuro, as entrevistas coincidiram com o momento em que Milton e a namorada faziam planos de se casar. Além disso, ele se cobrava em relação à continuidade dos estudos no ensino superior. Essas duas perspectivas de futuro - o casamento e a formação superior - situavam Milton em um momento em que ele se via (auto) pressionado a tomar decisões sobre o futuro.

Os educadores do MAC, o pastor e os amigos o incentivavam a cursar o ensino superior. Isso parecia se constituir para ele em um elemento de pressão e que se transformava em autocobrança. Ao mesmo tempo, se preparar para o vestibular significaria abrir mão de algumas atividades das quais gostava, como a de frequentar a igreja quase que diariamente. Sobre esta participação religiosa recorrente, Milton argumenta que a igreja teria o papel de substituir a sua família ausente, situação que lhe cobraria maior dedicação à igreja durante a semana comprometendo, consequentemente, o tempo que poderia dedicar à realização de um cursinho pré-vestibular. Assim, à medida que o tempo passava, ele desenvolvia um sentimento de culpa: "Meio que você está enterrando o seu talento!" (Carrano, 2008, p. 87). Ao mesmo tempo em que considerava que tinha potencial para cursar o ensino superior, Milton hesitava por achar que estava limitado para voltar a estudar. Apesar da trajetória escolar relativamente bem sucedida e de ser uma pessoa estudiosa, se deparava nesse momento com a consciência de horizontes possíveis encurtados.

Ao mesmo tempo, o contexto das entrevistas para a pesquisa parece ter influenciado no desejo de voltar a estudar. O ambiente, o contato com estudantes e pesquisadores, o deslocamento até a universidade para participar das entrevistas da pesquisa, pareceu fazer emergir em Milton o sonho, muitas vezes adiado, de fazer um curso universitário. Ele assim se manifestou sobre isso:

Ao mesmo tempo que é legal, às vezes eu fico meio tenso. [...] eu estou entrando aqui para fazer um trabalho, mas eu gostaria mesmo é de estar entrando para estar estudando, entendeu? Aí eu fico meio assim... Aí, às vezes eu me cobro muito. Às vezes eu fico chateado comigo mesmo. Eu falo assim: Pô, você podia estar aqui, cara! Você pode correr atrás. Você pode... Não sei... [...] Eu olho, assim... é meio que um sonho. Ao mesmo tempo que eu estou muito perto, eu estou muito longe, entendeu? Fisicamente. [...] Faculdade é um sonho. Como eu falei em outro depoimento, eu acho que é a herança que nos foi deixada. [...] Eu acho que de onde eu vim, hoje já está muito melhor. Aonde eu cresci, quem chegasse ao segundo grau era herói.

Esse sentimento de se situar num entrelugar, um perto-distante, um sonho com o qual pode conviver fisicamente com o deslocamento para a universidade durante as entrevistas, nos remete à experiência comum de jovens que, num contexto de inserção precária, convivem com promessas em vários âmbitos - formação, trabalho e consumo - ao mesmo tempo em que sentem o peso das limitações para a sua realização. Com a ampliação do acesso ao ensino médio e superior, muitos jovens tendem a experimentar com maior força o sentimento de que a

910 Educação \& Realidade, Porto Alegre, v. 38, n. 3, p. 895-914, jul./set. 2013. Disponível em: <http://www.ufrgs.br/edu_realidade> 
progressão na carreira escolar se distingue muito em virtude do pertencimento social de cada um.

Parece que o questionamento que Milton se fazia sobre se deixar consumir pelos outros como na referida metáfora da vela, estava ligado ao sentimento de autorresponsabilização por não conseguir concretizar o desejo de ingressar em um curso superior. Ao falar dessa questão ele dizia:

Você vê que ajuda as pessoas a crescer e você está definhando! [...] A parada é crescer juntos. [...] Eu tenho meus sonhos, minhas metas, não posso abrir mão disso por nada, entendeu? [...] Porque você não ainda não está na Faculdade? [pergunta a si mesmo].

\section{Considerações Finais}

A trajetória de Milton instiga-nos a pensar sobre algumas marcas da condição juvenil na sociedade brasileira. Em seu relato transparece a diversidade de relações sociais, espaços, práticas sociais e experiências que configuram o seu processo de socialização. A família, a escola e o trabalho não perdem a sua importância, mas se combinam com outros espaços e práticas sociais, como o grupo de amigos, a igreja e os projetos sociais. Tais experiências parecem ter contribuído para desenvolver determinadas disposições como uma tendência a investir nos estudos, a valorização da expressividade e das relações comunicativas, seja pela música, pelo uso da palavra na igreja (aconselhamentos e preleções) ou pelo gosto, habilidades e competências em artes plásticas que desenvolveu no projeto social promovido pelo MAC. Na perspectiva de Lahire (2002), trata-se de um conjunto de disposições heterogêneas e nem sempre coerentes, constituídas a partir da sua inserção em espaços, instituições e coletivos diversos.

Essas disposições ficaram muito evidentes na sua postura durante as entrevistas que revelaram se constituir em significativo campo de reflexividade para ele. Ao questionar sobre a sua trajetória de vida, os espaços que frequentava na cidade e o seu cotidiano, a pesquisa não apenas possibilitou o conhecimento da condição juvenil desse jovem, mas produziu um momento de autoanálise sobre a sua vida com suas conquistas, desafios, limitações e projetos futuros. A investigação social constitui-se então em um jogo relacional em que o pesquisador e o ator social entram em interação em torno de uma atividade reflexiva em que os dois estão na condição de observadores e de observados (Ranci, 2005). Sobre isso, foi eloquente a sua afirmação de que a pesquisa teria afirmado a "[...] necessidade de o jovem ser ouvido".

O cotidiano de Milton era marcado por uma heterogeneidade de atividades, de tempos e de espaços. Dias e semanas lentos se alternavam com outros repletos de tarefas, tempos velozes e intensos. Espaços e momentos de intimidade intercalados com a exposição pública. Como educador social e liderança juvenil Milton assumia uma série de tarefas, nas quais ele se consumia para se manter visível, inserido em sua

Educação \& Realidade, Porto Alegre, v. 38, n. 3, p. 895-914, jul./set. 2013.

Disponível em: <http://www.ufrgs.br/edu_realidade> 
rede de contatos e amizades. Cotidianos vividos com estranhamento por ele quando as atividades se tornavam mais esparsas.

A trajetória de Milton revela também a presença de situações e experiências que remetem ao que Araújo e Martuccelli (2010) denominaram de provas estruturais. Vistos da perspectiva da posição social, os aspectos destacados por ele são comuns à maioria dos indivíduos dos meios populares. O desafio da escolarização, a luta pela inserção profissional e os preparativos para a formação de um novo lar revelam os impactos da distribuição desigual dos recursos econômicos e sociais. Mas, tomados na singularidade da trajetória desse jovem, elas assumiram contornos próprios. Por exemplo, na esfera das relações de sociabilidade, o desafio de ser respeitado entre os colegas nos primeiros anos de vida, as relações com os amigos do funk, a convivência com o tráfico de drogas desenham os contornos singulares da construção de si no contexto da vida no morro.

Apesar das dificuldades vividas pela sua condição social, principalmente em relação à busca de inserção em um trabalho permanente, ele conseguiu formular estratégias e desenvolveu aprendizados que lhes permitiram vislumbrar alternativas de projetos futuros. Certamente a vida lhe colocou muitas provas - um amadurecimento antecipado, uma disciplina constante, se tornar homem cedo, acumular muitas atividades, ter uma casa para cuidar sozinho - mas, ao mesmo tempo foram experiências que lhe permitiram desenvolver certas habilidades e saberes que lhe acenam alguma perspectiva de vida futura como educador social.

Ficou evidente a importância na sua vida das experiências que teve nos projetos sociais dos quais participou. Para além da consideração de que muitas dessas iniciativas foram pontuais e precárias, o vínculo construído com um desses projetos em especial permitiu a ele inserir-se em uma rede de relações sociais e desenvolver saberes e aprendizados importantes para a sua vida. Em síntese, Milton constituiu capital social individualizado (Pimenta, 2007) que o lançou para além das condições objetivas do seu contexto social.

Recebido em 26 de outubro de 2011 Aprovado em 06 de março de 2012

\section{Notas}

1 Projetado pelo arquiteto Oscar Niemeyer e inaugurado em 1996, o MAC desenvolve vários projetos educativos voltados para escolas, moradores, jovens e crianças. Confira <http://www.macniteroi.com.br>.

2 Nome fictício.

3 Juventude, para efeitos deste texto, é uma categoria sociológica concebida como uma construção histórico-social da modernidade, que envolve, mas não se limita ao recorte etário e biológico instituído jurídica e socialmente. Cf. Sposito (2000).

4 O termo movimentorefere-se ao tráfico de drogas ilícitas nos morros fluminenses.

912 Educação \& Realidade, Porto Alegre, v. 38, n. 3, p. 895-914, jul./set. 2013. Disponível em: <http://www.ufrgs.br/edu_realidade> 
5 O Programa Capacitação Solidária foi criado, em 1996 e financia projetos de capacitação profissional para jovens de 16 a 21 anos, com baixa escolaridade e provenientes de famílias baixa renda. Ele é um dos programas do Programa Comunidade Solidária, que foi coordenado pela socióloga Ruth Cardoso, primeira-dama do Brasil durante os dois mandatos do Presidente Fernando Henrique Cardoso (1995 - 2002).

6 Projeto desenvolvido pelo Governo do Estado do Rio de Janeiro através da Secretaria de Desenvolvimento Comunitário a partir de 2002.

7 Favela do município do Rio de Janeiro.

\section{Referências}

ABRANTES, Pedro; GUERREIRO, Maria das Dores. Como Tornar-se Adulto: processos de transição na modernidade avançada. Revista Brasileira de Ciências Sociais, São Paulo, v. 20, n. 58, jun. 2005. Disponível em: <http://www.scielo.br/pdf/rbcsoc/ v20n58/25633.pdf>. Acesso em: 01 jun 2005.

ARAÚJO, Káthya; MARTUCCELLI, Danilo. La Individuación y el Trabajo de los Indivíduos. Educação e Pesquisa, São Paulo, v. 36, n. esp., p. 77-91, abr. 2010.

ARNETT, Jeffrey Jensen. Conceptions of the Transition to Adulthood: perspectives from adolescence to midlife. Journal of Adult Development, [New York?], v. 8, n. 2, p. 133-143, 2001.

BOURDIEU, Pierre. Esboço de uma Teoria da Prática. In: ORTIZ, Renato (Org.). Pierre Bourdieu: Sociologia. São Paulo: Ática, 1983. P. 46-81

BOURDIEU, Pierre. A Ilusão Biográfica. In: Ferreira, Marieta de Moraes; AMADO, Janaina (Org.). Usos e Abusos da História Oral. Rio de Janeiro: FGV, 1996. P. 183-191.

CAMARANO, Ana Amélia. Considerações Finais: transição para a vida adulta ou vida adulta em transição? In: CAMARANO, Ana Amélia (Org.). Transição Para a Vida Adulta ou Vida Adulta em Transição? Rio de Janeiro: Ipea, 2006. P. 319-330.

CAMARANO, Ana Amélia; MELLO, Juliana Leitão; KANSO, Solange. Do Nascimento à Morte: principais transições. In: CAMARANO, Ana Amélia (Org.). Transição Para a Vida Adulta ou Vida Adulta em Transição? Rio de Janeiro: Ipea, 2006. P. 31-60.

CARRANO, Paulo Cesar Rodrigues. Percursos urbanos de jovens de espaços populares: usos da cidade e modos de vida. Diário de campo. 2008. Programa de Pós-Graduação em Educação. Universidade Federal Fluminense, Niterói, Rio de Janeiro.

CARRANO, Paulo Cesár Rodrigues. Juventude as Identidades são Múltiplas. Movimento: Revista da Faculdade de Educação da Universidade Federal Fluminense, Niterói, n. 1, p. 11-27, maio 2000.

CHARLOT, Bernard. Da Relação com o Saber. Elementos para uma teoria. Porto Alegre: Artmed, 2000.

DÁVILA, Oscar; GHIARDO, Felipe; MEDRANO, Carlos. Los Desheredados: trayectorias de vida y nuevas condiciones juveniles. Santiago, CL: CIDPA Ediciones, 2005. DEBERT, Guita Grin. A Reinvenção da Velhice. São Paulo: Edusp: Fapesp, 1999.

DUBAR, Claude. Trajetórias Sociais e Formas Identitárias: alguns esclarecimentos conceituais e metodológicos. Educação \& Sociedade, Campinas, v. 19, n. 62, abr. 1998. Disponível em: <http://www.scielo.br/scielo.php?script=sci_arttext\&pid=S0101$73301998000100002 \& \operatorname{lng}=$ en\&nrm=iso $>$. Acesso em: 01 jun 2010.

DUBET, François. Des Jeneusses et des Sociologies : le cas français. Sociologie et Societé, Les Jeunes, Montreal, v. 28, n. 1, p. 13-22, printemps 1996. 
LAHIRE, Bernard. Sucesso Escolar nos Meios Populares: as razões do improvável. São Paulo: Editora Ática, 1997.

LAHIRE, Bernard. O Homem Plural. Petrópolis, RJ: Vozes, 2002.

LAHIRE, Bernard. Retratos Sociológicos: disposições e variações individuais. Porto Alegre: Artmed, 2004.

LECCARDI, Carmen. Por um Novo Significado do Futuro: mudança social, jovens e tempo. Revista de Sociologia da USP, São Paulo, v. 17, n. 2, p. 35-57, nov. 2005.

MARTUCCELLI, Danilo. Cambio de Rumbo: la sociedad a escala del individuo. Santiago: LOM, 2007.

MELUCCI, Alberto. O Jogo do Eu: a mudança de si em uma sociedade global. São Leopoldo: Editora Unisinos, 2004.

PAIS, José Machado. Ganchos, Tachos e Biscates: jovens, trabalho e futuro. Porto: Ambar, 2001.

PERALVA, Angelina Teixeira. Violência e Democracia: o paradoxo brasileiro. Rio de Janeiro: Paz e Terra, 2000.

PIMENTA, Melissa de Mattos. "Ser Jovem" e "Ser Adulto": identidades, representações e trajetórias. 2007. 463 f. Orientadora: Maria Helena Oliva Augusto, Tese (Doutorado em Sociologia) - Faculdade de Filosofia, Letras e Ciências Humanas, Universidade de São Paulo, São Paulo, 2007.

RANCI, Constanzo. Relações Difíceis: a interação entre pesquisadores e atores sociais. In: MELUCCI, Alberto. Por uma Sociologia Reflexiva. Petrópolis: Vozes, 2005. P. 43-66.

SARTI, Cynthia Andersen. A Família Como Espelho: um estudo sobre a moral dos pobres. Campinas: Autores Associados, 1996.

SPOSITO, Marília Pontes. Considerações em Torno do Conhecimento Sobre Juventude na Área da Educação: relatório. In: SPOSITO, Marília Pontes (Org.). Estado do Conhecimento: juventude e escolarização. São Paulo: CNPq/FAPESP/INEP, 2000. 317 f. Disponível em: <www.acaoeducativa.org>.

Geraldo Magela Pereira Leão é professor adjunto da Faculdade de Educação e do Programa de Pós-Graduação em Educação, Conhecimento e Inclusão Social da UFMG. Doutor em Educação pela Universidade de São Paulo (2004). Fez o Pós-Doutorado em Educação pela Universidade Federal Fluminense em 2009. Pesquisador do Observatório da Juventude da UFMG.

E-mail: gleao2001@yahoo.com.br

Paulo César Rodrigues Carrano é professor Associado I da Faculdade de Educação e integrante do Programa de Pós-Graduação em Educação da UFF Faculdade de Educação da Universidade Federal Fluminense. Doutor em Educação (UFF - 1999). Realizou dois estágios de pós-doutoramento (USP e Universidade de Lisboa). É bolsista produtividade nível 2 do CNPq. Coordenador do Grupo de Pesquisa Observatório Jovem do Rio de Janeiro/UFF. E-mail:pc.carrano@gmail.com

914 Educação \& Realidade, Porto Alegre, v. 38, n. 3, p. 895-914, jul./set. 2013 Disponível em: <http://www.ufrgs.br/edu_realidade> 